\title{
Simulated Performances of a Heat Pump System for Energy and Water Conservation in Open and Confined Greenhouse Systems
}

\author{
I. Yildiz \\ Department of Earth and Env. Sciences \\ University of Windsor \\ Windsor, Ontario, N9B 3P4 \\ Canada
}

\author{
D.P. Stombaugh \\ Department of Agricultural, Food, \\ and Biological Engineering \\ The Ohio State University \\ Columbus, OH 43210 \\ USA
}

Keywords: energy conservation, water conservation, simulation, ventilation, transpiration, evaporative cooling, greenhouse heating and cooling, enclosed agro-ecosystem

\begin{abstract}
The purpose of this study was to determine and compare the performances of conventional and heat pump systems for energy and water conservation in open and confined greenhouse systems. Conventional gas furnaces and evaporative cooling, respectively, provided heating and cooling in the conventional system. In the heat pump systems, gas-fired heat pump units provided both heating and cooling. The greenhouse with heat pump units also had an option to be operated as a completely confined system, using one of the heat pump units as a dehumidifier. Average energy consumption in winter was 56.9, 23.5, and $11.3 \mathrm{MJ} / \mathrm{day}_{\mathrm{m}} \mathrm{m}^{2}$ in the conventional, open, and closed loop (confined) heat pump systems, respectively. In spring, the same greenhouse systems averaged 20.6, 8.8, and $5.3 \mathrm{MJ} / \mathrm{day}^{2} \mathrm{~m}^{2}$, respectively. In summer, energy consumption was considerably less than those predicted for winter and spring. The major portion of the total energy consumption was for heating. Daily transpiration rates averaged for winter, spring, and summer were $2.09,2.02$, and $1.02 \mathrm{~kg}$ $\mathrm{H}_{2} \mathrm{O} /$ day. $^{2}$ in the conventional, open, and closed loop heat pump systems, respectively. In the closed loop system, almost all the transpired water was recovered on the cooling coils, making the overall water consumption in this system essentially zero. This study concluded that greenhouse operation with the heat pump system has a great potential for enormous energy, water, and $\mathrm{CO}_{2}$ savings, as well as cooling and dehumidification. A confined greenhouse with a heat pump system would make it easier to control the humidity and keep high $\mathrm{CO}_{2}$ levels, while reducing the risk of insects and diseases. A combination of open and closed loop systems would be the most energy conserving system, operating the system as a closed loop system in winter, spring and fall, and as an open system in summer.
\end{abstract}

\section{INTRODUCTION}

To provide economically optimal micro-environments for plant growth, producers can use or control the number of glazing layers, insulation curtains or screens to reduce long-wave radiation losses at night, reduced ventilation rates, evaporative coolers, and shading devices to control incoming solar radiation. In addition, a Rankine cycle heat pump that was developed by Yildiz (1993), and Yildiz et al. (1993) holds promise for reducing winter heating requirements and warm weather cooling loads. These systems involve complex tradeoffs between initial and operating costs for cooling and heating, plant responses to various environmental factors and the strategies used to regulate temperature, humidity and $\mathrm{CO}_{2}$ levels in the crop canopy. Special attention must also be given to the operational strategies associated with the use of heat pumps, especially in maintaining acceptable relative humidity levels within greenhouses.

A dynamic simulation model was developed and validated to provide an accurate prediction of greenhouse energy and moisture exchanges as a function of dynamic environmental factors (Yildiz and Stombaugh, 2006). This model was used to predict heating and cooling loads, water use, and to evaluate the operational strategies associated with heating and cooling using the proposed heat pump and a conventional system. The 
heat pump was evaluated for both open and closed loop systems, and these were compared to a conventionally ventilated and heated greenhouse. The overall objective of this study was to compare conventional, open loop and closed loop heat pump greenhouse systems in terms of energy and water conservation.

\section{PROCEDURES}

\section{Weather File}

January, April, and July weather files for Delaware (latitude $40^{\circ} 17^{\prime} \mathrm{N}$, longitude $83^{\circ} 05^{\prime} \mathrm{W}$ ), Ohio, USA were used to represent winter, spring, and summer in the simulations. Simulations were performed starting at the beginning of the fifth day and ended at the end of the 29th day of the month providing a 25-day simulation.

\section{Greenhouse Characteristics, Heating, Cooling, Ventilation, and Shading}

A dynamic computer simulation model to determine greenhouse microclimates was developed and validated. Table 1 shows the greenhouse and the crop characteristics used in this study. Yildiz and Stombaugh (2006) reported the theoretical approach, model validation, and all the other greenhouse and crop characteristics. The heat pumps evaluated for open (OHP) and closed loop (CHP) greenhouse systems were 3-ton (based on system heat removal capacity) gas fired units, and to provide multiposition proportional control it was assumed that 3 units were used in each greenhouse. The heat pump consists of a Rankine power cycle and a vapor compression cycle which uses a novel hydraulically connected rolling diaphragm piston cylinder device as motor, compressor and pump (Yildiz, 1993; Yildiz et al., 1993). R123 (dichlorotrifluoroethane) and R22 (chlorodifluoromethane) refrigerants were used for the power and refrigeration cycles, respectively. For the conventional greenhouse $(\mathrm{CON})$ simulations, it was assumed that the conventional gas-fired furnace provided $24,612 \mathrm{~W}$ of heat input each. A furnace efficiency of 0.7 was assumed for the conventional heating system (Badger and Pole, 1979). No heat storage facility was used in this study. An overhead plastic tube was used for the hot and the cold air distribution in both heating and cooling modes. One of the heat pump units in the closed loop (completely confined) greenhouse system was used as a dehumidifier while operating as a heater. The only difference from the original heating unit was circulating the inside greenhouse air through the outdoor coil instead of the outside air. This prevented moisture build up in the confined greenhouse system. During the winter season, $0.943 \mathrm{~m}^{3} / \mathrm{s}$ of inside air passed through the condensers, and $2.829 \mathrm{~m}^{3} / \mathrm{s}$ of inside air was passed through the outside evaporator, which provided the dehumidification. An evaporative cooler was employed for cooling the conventional greenhouse. In the open and closed loop greenhouse systems, however, the heat pump units provided the cooling requirements in the greenhouse. Outdoor air was used in the evaporative cooling system, and it was assumed that the air at the evaporative cooler outlet was fully saturated. In the heat pump systems, indoor air was recirculated and introduced back to the inside at a lower temperature.

Two shading clothes with transmissivities of 0.75 and 0.50 were used to reduce the cooling loads. The use of these shading clothes provided shading levels of $25 \%, 50 \%$ and $62.5 \%$ by using them individually or together. An aluminized (both sides) night curtain was used at night to reduce the heat loss due to long-wave radiation exchanges between the inside greenhouse components and the sky. In the open systems (CON and OHP), ventilation was provided by two fans, one with a fixed flow rate to provide a minimum level of air exchange at all times, and the other one with a variable flow rate.

\section{Operational and Control Strategies}

The day or nighttime greenhouse temperature set points were based on the solar position. Based on the indoor air temperature, the control system operated in either the heating or cooling mode. If the system was in heating mode and if heating was required, the ventilation rate was first set to the minimum rate. The control system turned on other 
heating units based on the difference between the indoor and set point temperatures, providing a multi-position proportional control. If no heating was required in this mode no heating unit operated; but the system remained in the heating mode until it was switched to the cooling mode.

The cooling mode operated in two steps. The first step was to reduce the cooling load using a variable shading system and to cool the inside air by increasing ventilation rates. Two shading cloths provided the variable shading with transmissivities of 0.75 and 0.50 used individually or together. The minimum and maximum ventilation rates were $0.01 \mathrm{~m}^{3} / \mathrm{s} . \mathrm{m}^{2}$ and $0.08 \mathrm{~m}^{3} / \mathrm{s} . \mathrm{m}^{2}$, respectively. If the first step in cooling could not handle the cooling load, then the second step was activated, in which the heat pump units (OHP) or evaporative cooling (CON) provided the cooling. In the conventional system, introducing an outside airflow rate of $0.08 \mathrm{~m} / \mathrm{s} . \mathrm{m}^{2}$ when the second step was activated in the cooling mode provided evaporative cooling. Relative humidity levels in the conventional system were controlled indirectly by the temperature control. In the open loop heat pump system, however, additional relative humidity control was provided. When the inside relative humidity levels exceeded $80 \%$, additional ventilation was introduced to decrease inside relative humidity. In the closed loop system, the same criterion was used to prompt the heating mode. However, the cooling mode was activated at lower inside temperatures than those used in the other two systems. The operation of the heating system was the same as in the other two systems. However, the minimum ventilation rate was used in the open loop system while no ventilation was used in this confined system. In the cooling mode of the closed loop system, there was only one step unlike the conventional and open loop systems, which had two-step cooling systems. Here, no cooling was provided by ventilation; instead, the cooling was provided by the three heat pump units providing a multiposition proportional control, after reducing the cooling load using the variable shading system. The operation of the shading system was the same as in the other two systems. Either the cooling units or the dehumidifier (the first heating unit) controlled inside relative humidity. When the inside relative humidity levels exceeded $80 \%$, this heating unit operated as a dehumidifier to prevent excess moisture within the closed loop heat pump system.

\section{RESULTS AND DISCUSSION}

Fig. 1 presents the predicted hourly transpiration and energy consumption rates per unit ground area in the conventional, open and closed loop heat pump greenhouse systems for 10 successive days in winter. In Fig. 1, only 10-day simulation results were presented to show the long-term operation of the simulation model and behavior of the climatic quantities. These 10-day simulations were obtained from 25-day simulation runs ignoring the first 6 and last 9 days of the simulations.

Fig. 1a shows predicted hourly transpiration and energy consumption rates per unit ground area for the outside climatic conditions shown in a conventional greenhouse system in winter. The highest transpiration rate occurred on the fifth day (at noon) with a rate of approximately $0.24 \mathrm{~kg} / \mathrm{hr} \cdot \mathrm{m}^{2}$. This was due to the high outside solar radiation and the low outside relative humidity levels on that particular day. The low outside temperature and relative humidity resulted in low relative humidity levels and bigger vapor pressure deficits inside. As a result of this combination, higher transpiration rates were observed on the fifth day compared to the other days. At night however, the transpiration rates were at approximately $0.10 \mathrm{~kg} / \mathrm{hr} \cdot \mathrm{m}^{2}$ except for the ninth day on which both night and daytime transpiration rates were considerably lower than the rates on the other days. This was partly due to the very low outside solar radiation (about $50 \mathrm{~W} / \mathrm{m}^{2}$ ) for the duration of only two or three hours. Another cause for these low rates was the high outside relative humidity and air temperatures during the day. Fig.1 a also shows that the highest energy consumption rates occurred at very early hours on the second and fifth days due to the low outside air temperatures. The low outside temperatures resulted in lower inside temperatures increasing the inside relative humidity levels. This high relative humidity levels called for heating, eventually increasing the energy consumption. The 
energy consumption rates were about $4000 \mathrm{~kJ} / \mathrm{hr}^{-\mathrm{m}^{2}}$ on both days. The minimum energy consumption occurred on the seventh day, on which the air temperatures were comparatively higher.

Fig. 1b shows that the transpiration rates in the open loop heat pump greenhouse system were almost the same as in the conventional system. This was due to the fact that the indoor conditions were very similar, and nearly identical control strategies were used for both systems in cold weather. While the trends in energy consumption rates were the same as in the conventional system, the magnitudes were considerably lower. The highest energy consumption for heating in the conventional system was about $4000 \mathrm{~kJ} / \mathrm{hr} . \mathrm{m}^{2}$, whereas it was about $1500 \mathrm{~kJ} / \mathrm{hr}^{2} \mathrm{~m}^{2}$ in the open loop heat pump system. This resulted from the efficiency differences between the two heating systems. The average COP's (coefficient of performance) for the heating units were 0.70 and 1.78 for the conventional furnace and open loop heat pump systems, respectively. That is, the conventional gas furnace consumed about 2.5 times more energy than the proposed heat pump system to heat the same size greenhouse.

Fig. 1c shows that the only differences between the closed loop system and the other two systems were the magnitudes of the transpiration rates and the fact that almost all the water transpired was condensed on either the dehumidifier coil or the cooling unit coil. The highest transpiration rate was about $0.12 \mathrm{~kg} / \mathrm{hr} \cdot \mathrm{m}^{2}$ on the fifth day while the minimum rate was about $0.02 \mathrm{~kg} / \mathrm{hr}^{2} \mathrm{~m}^{2}$, primarily at night. Transpiration rate was lower in the closed loop system because the inside relative humidities were approximately $20 \%$ higher. High inside humidity levels reduced the vapor pressure deficit, and therefore the transpiration rates. Since almost all the water transpired by plants was collected on the coils, water use in a closed loop heat pump system was essentially zero. Fig. 1c also shows that the closed loop heat pump system had the lowest heating energy consumption of all three systems. The highest and lowest energy consumption rates occurred on the same days as in the other two systems due to the same outside climatic conditions. However, the highest heating energy consumption rate was only about $750 \mathrm{~kJ} / \mathrm{hr}^{2} \mathrm{~m}^{2}$ observed early in the morning on the second and fifth days, whereas the lowest energy consumption rate was observed on the seventh day with a rate of about $100 \mathrm{~kJ} / \mathrm{hr}^{2} \mathrm{~m}^{2}$. The reason for the closed loop heat pump system having low water use (transpiration) and energy consumption was due to the fact that there was no ventilation in this greenhouse system. This resulted in a moisture build up and high humidity levels (between $70 \%$ and $90 \%$ ) within the greenhouse. No ventilation also meant that no heat loss or gain occurred via ventilation. Therefore, although both the open and closed loop heat pump greenhouse systems used the same heating systems, the energy consumption rates were considerably different in these two systems.

Table 2 summarizes the daily averages of energy consumption and transpiration rates in conventional, open, and closed loop heat pump greenhouse systems in winter, spring, and summer. The conventional system used considerably more energy than the other two systems in winter and spring. In winter, average daily heating energy consumption per unit ground area were $56.9,23.5$ and $11.3 \mathrm{MJ} /$ day. $^{2}$ in conventional, open, and closed loop heat pump greenhouse systems, respectively. Whereas in spring, the average consumptions in the same greenhouse systems were $20.6,8.8$, and $5.3 \mathrm{MJ} / \mathrm{day} . \mathrm{m}^{2}$, respectively. In summer, however, the average daily energy consumption were considerably less than those in winter and summer, and the closed loop heat pump system had the highest energy consumption. The major portion of the total energy consumption was for heating in all the greenhouse systems (Table 2 and Fig. 2). The energy used for cooling and ventilation was of much less importance, because the shading reduced the required cooling loads. Also the plants themselves are biological humidifiers and can provide much of their own cooling.

Fig. 2 shows the average daily energy consumption in winter, spring, and summer when all three were averaged together. The conventional system $\left(26.1 \mathrm{MJ} /\right.$ day.m $\left.{ }^{2}\right)$ consumed about 2.3 and 3.2 times more energy than the open loop heat pump (11.5 $\mathrm{MJ} /$ day. $\left.^{2}\right)$ and the closed loop heat pump $\left(8.3 \mathrm{MJ} /\right.$ day. $\left.\mathrm{m}^{2}\right)$ systems, respectively. In the 
conventional greenhouse system, $99.5 \%$ of the energy consumption was used for heating, while the remaining was used for ventilation. Evaporative cooling in the conventional system provided the cooling in summer. In the open loop heat pump system, $94.2 \%$ of the total energy consumption was used for heating, while $3.1 \%$ was used for ventilation, and $2.7 \%$ was used for cooling. In the closed loop heat pump system however, $70 \%$ of the total energy consumption was used for heating, while $30 \%$ was used for cooling.

Table 2 also summarizes the water consumption and collection rates in different greenhouse systems. Higher transpiration rates were predicted in winter than in spring and summer in the conventional and open loop heat pump systems, even though lower solar radiation levels were observed in winter. However, low outside and inside relative humidities occurred in winter, and this was the driving force, which caused the increased transpiration rates. The transpiration rates in the conventional and open loop heat pump systems were about the same in winter and spring. In summer, however, the transpiration rates in the open loop heat pump system were higher than those in the conventional system. This was due to the high relative humidity levels and small vapor pressure deficits in the conventional system as a result of evaporative cooling. The difference in transpiration rates in the closed loop heat pump system with respect to different months, however, was mostly the result of the increased solar radiation rather than the vapor pressure deficit, because the inside relative humidity levels were kept at about the same levels. Since the inside relative humidity was maintained at higher levels (80-95\%) in the closed loop heat pump system compared to the other two systems, the transpiration rates in this system were lower than those in the other two systems. Average daily transpiration rates of winter, spring and summer were $2.09,2.02$, and $1.02 \mathrm{~kg} / \mathrm{day} \cdot \mathrm{m}^{2}$ in the conventional, open loop heat pump, and closed loop heat pump systems, respectively.

In addition to the transpiration, water was also used for evaporative cooling in the conventional system (Table 2). On the other hand, in the closed loop system, almost all the transpired water was recollected on the coils, making the overall water consumption in the closed loop heat pump system essentially zero. Thus, the closed loop heat pump system was the most energy and water conserving system, while the conventional system used the most energy and water of all the systems in this study.

\section{CONCLUSIONS}

This study concluded that greenhouse operation with the heat pump system has a great potential for enormous energy and water savings, as well as cooling and dehumidification. Closed loop greenhouse operation with a heat pump system would make it easier to control the humidity and keep high $\mathrm{CO}_{2}$ levels, while reducing the risk of insects and diseases within the confined greenhouse environment. The heat pump system performed very well with a variable shading system significantly conserving both energy and water. The cooling system COP varied from 0.93 to 1.03 , whereas the heating system COP varied from 1.64 to 1.81 . A combination of open and closed loop systems would be the most energy and water conserving system, operating the system as a closed loop system in fall, winter and spring, and as an open loop system in summer. However, commercial feasibility of this heat pump system depends on the initial investment for the heat pump unit. Preliminary estimates showed that combination systems can easily payback the initial investment for the heat pump system in a couple years.

\section{ACKNOWLEDGEMENTS}

American Society of Heating, Refrigerating, and Air-Conditioning Engineers, Inc. and Ohio Super Computing Center provided partial funding for this study.

\section{Literature Cited}

Badger, P.C. and Poole, H.A. 1979. Conserving energy in greenhouses. OARDC Special Cir. 102, Extension Bul. 651, p.32. Ohio Agricultural Research and Development Center, Wooster, Ohio, USA.

Yildiz, I. 1993. A performance study of a Rankine cycle driven heat pump system. M.S. 
Thesis, The Ohio State University, Columbus, Ohio, USA.

Yildiz, I., Lin, C. and Christensen, R.N. 1993. A performance study of a Rankine cycle driven heat pump system. AES-Vol. 29, Heat Pump and Refrigeration Systems Design, Analysis, and Applications, ASME 1993, USA. p.9-18.

Yildiz, I. and Stombaugh, D.P. 2006. Dynamic modeling of microclimate and environmental control strategies in a greenhouse coupled with a heat pump system. Acta Hort. 718:331-339. 
$\underline{\text { Tables }}$

Table 1. Greenhouse and crop characteristics used in the simulation model.

Greenhouse length

Greenhouse width

Greenhouse height at eaves

Greenhouse height at ridges

Glazing

Floor surface material

Crop type

Crop row orientation

Distance between plant rows

Avg. leaf length

Avg. leaf width
$7.5 \mathrm{~m}$ (Conventional and OHP) and $25.0 \mathrm{~m}$ (CHP)

$7.50 \mathrm{~m}$

$2.50 \mathrm{~m}$

$4.50 \mathrm{~m}$

Double polyethylene

Reflective mulch

Cucumber

North - South

$0.75 \mathrm{~m}$

$0.30 \mathrm{~m}$

$0.25 \mathrm{~m}$

OHP: Open loop heat pump system; CHP: Closed loop heat pump system

Table 2. Daily energy consumption and water use in conventional (CON), open loop (OHP), and closed loop heat pump (CHP) systems in winter, spring, and summer.

\begin{tabular}{|c|c|c|c|c|c|c|c|c|c|}
\hline & \multicolumn{3}{|c|}{ Winter } & \multicolumn{3}{|c|}{ Spring } & \multicolumn{3}{|c|}{ Summer } \\
\hline & CHP & OHP & CON & CHP & OHP & CON & CHP & OHP & CON \\
\hline \multicolumn{10}{|c|}{$\begin{array}{l}\text { ENERGY CONSUMPTION } \\
\left(\mathrm{MJ} / \text { day. } \mathrm{m}^{2}\right)\end{array}$} \\
\hline \multicolumn{10}{|l|}{ Heating } \\
\hline Natural Gas & 10.75 & 22.22 & 56.72 & 5.04 & 8.36 & 20.54 & 0.66 & 0.09 & 0.44 \\
\hline Fan (Electric) & 0.44 & 0.91 & 0.20 & 0.20 & 0.36 & 0.07 & 0.03 & * & * \\
\hline Pump (Electric) & 0.16 & 0.32 & ---- & 0.07 & 0.12 & ---- & 0.01 & * & ---- \\
\hline Subtotal & 11.34 & 23.45 & 56.92 & 5.31 & 8.82 & 20.61 & 0.70 & 0.10 & 0.44 \\
\hline \multicolumn{10}{|l|}{ Cooling } \\
\hline Natural Gas & 0.02 & ---- & ----- & 1.94 & ----- & ----- & 5.19 & 0.91 & ---- \\
\hline Fan (Electric) & * & ----- & ----- & 0.05 & ----- & ----- & 0.14 & 0.02 & ---- \\
\hline Pump (Electric) & $*$ & ---- & ---- & 0.03 & ---- & ---- & 0.08 & 0.01 & ---- \\
\hline Subtotal & 0.02 & ----- & ----- & 2.02 & ----- & ----- & 5.40 & 0.94 & --- \\
\hline Ventilation & ---- & 0.11 & 0.11 & ----- & 0.23 & 0.11 & ---- & 0.71 & 0.13 \\
\hline TOTAL & 11.36 & 23.56 & 57.03 & 7.33 & 9.04 & 20.73 & 6.10 & 1.75 & 0.57 \\
\hline \multicolumn{10}{|c|}{$\begin{array}{l}\text { WATER CONSUMPTION } \\
\left(\mathrm{kg} \mathrm{H}_{2} \mathrm{O} / \text { day. }^{2}\right)\end{array}$} \\
\hline Transpiration & 0.85 & 2.52 & 2.54 & 1.05 & 2.22 & 2.17 & 1.17 & 1.66 & 1.28 \\
\hline Water Collected & 0.83 & ----- & ----- & 1.04 & ----- & ----- & 1.17 & 0.35 & ---- \\
\hline Evaporative Cooling & ----- & ----- & ----- & ----- & ----- & ----- & ----- & ----- & 0.29 \\
\hline TOTAL & 0.02 & 2.52 & 2.54 & 0.01 & 2.22 & 2.17 & 0.00 & 1.31 & 1.57 \\
\hline
\end{tabular}

* Negligible amount 


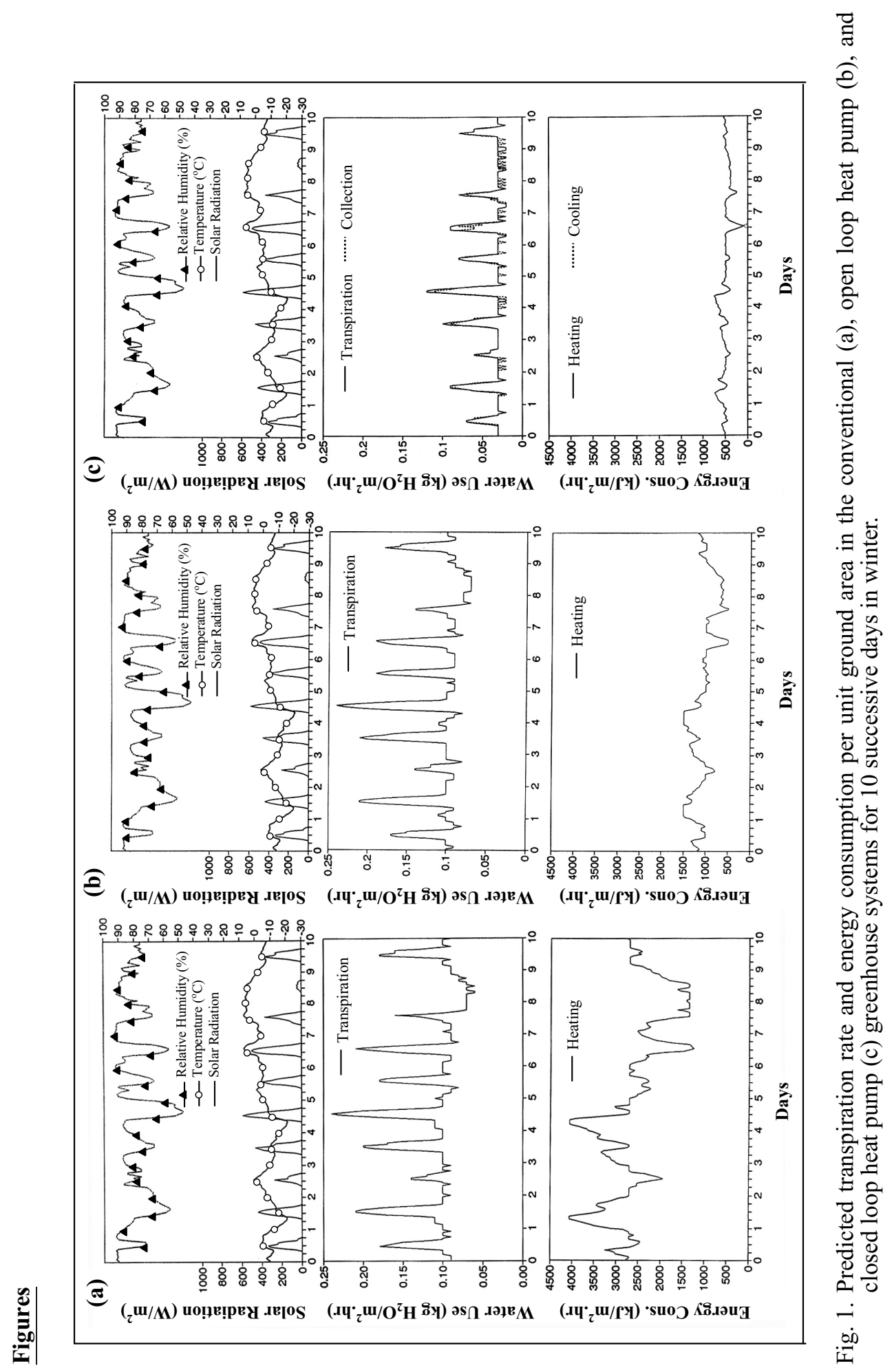




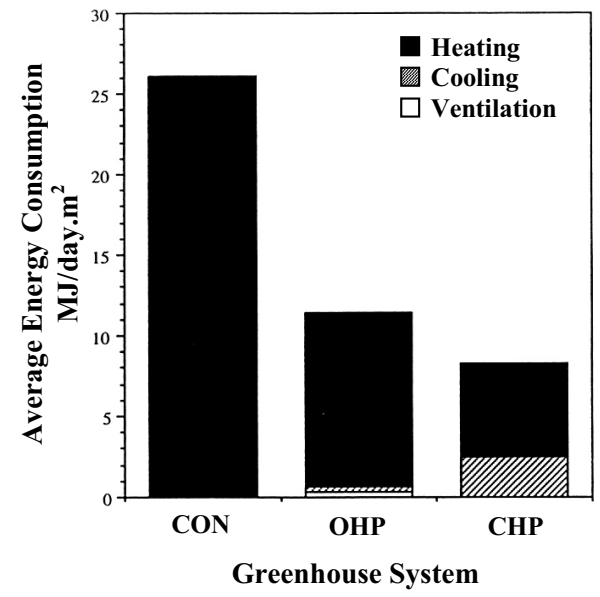

Fig. 2. Average of winter, spring, and summer energy consumption in conventional (CON), open loop (OHP), and closed loop heat pump (CHP) systems. 